\title{
DETERMINATION OF AN EXTRAGALACTIC RADIO SOURCE POSITION CATALOGUE SUITABLE FOR USE IN MONITORING GEOPHYSICAL PHENOMENA
}

\author{
JOHN L. FANSELOW and J. G. WILLIAMS \\ Jet Propulsion Laboratory, California Institute of Technology, Pasadena, Calif., U.S.A.
}

\begin{abstract}
The use of radio interferometric techniques to monitor geophysical phenomena such as UT1-UTC variations, polar motion, and tectonic plate motion requires that there be available a fairly uniform distribution of extragalactic radio sources whose relative positions are known to better than 0.01 . These sources must also have very small proper motion, and not be subject to asymmetric changes in radio structure or to very large variations in intensity. In addition, to facilitate tying this frame of reference to the optical star frames, it is desirable that many of these radio objects have optical counterparts. This paper describes our progress in obtaining such a frame and sets forth our desiderata for further work by radio and optical astronomers.
\end{abstract}

\section{DISCUSSION}

Murray: As an optical astronomer in the radio source position business I would like to know when we can expect a definitive list of compact sources, at say 0.02 , which are suitable for position calibration. Otherwise we waste large-telescope time getting plates on useless sources.

Williams: About 75 sources have been seen at our wavelength $(13 \mathrm{~cm})$ in very long baseline interferometry experiments. These are sources which have at least one compact component at the $\$ 0$ ".002 level. They may, however, have larger scale structure too. We will make a list of these sources available to interested workers. Of these sources 25 have been used to make a preliminary radio catalogue based on the interferometry data.

Walter: What is the distribution in declination of the catalogued radio sources?

Williams: From $-16^{\circ}$ to $+69^{\circ}$ in the extreme. Most of the sources lie between $0^{\circ}$ and $+50^{\circ}$. 